\title{
Analisa Faktor-Faktor yang Mempengaruhi Kualitas Laporan Keuangan (Studi pada Kementerian Kesehatan)
}

\author{
Alvi Syahri Ramadhan Nasution ${ }^{(1)}$, Ida Farida ${ }^{(2)}$, Sofik Handoyo ${ }^{(3)}$ \\ Universitas Padjadjaran \\ Jl. Raya Bandung-Sumedang Km. 21 Jatinangor \\ Telp./Fax. (022) 84288888/(022) 84288898 Kab. Sumedang 45363 Jawa Barat \\ e-mail: alvi.ramadhan@bpk.go.id
}

\begin{abstract}
ABSTRAK
Instansi Pemerintah masih mengalami banyak kendala dalam menyusun Laporan Keuangan yang berkualitas. Penelitian ini bertujuan untuk mengidentifikasi faktor penyebab kendala penyusunan Laporan Keuangan yang berkualitas. Teori dua faktor (Hezberg's Motivation and Hygiene Theory) dan penelitianpenelitian sebelumnya mengindikasikan bahwa motivasi dan lingkungan kerja (Hygiene) mempengaruhi kinerja pegawai yang bertugas menyusun Laporan Keuangan. Selain motivasi, kompetensi pegawai yang ikut mempengaruhi kualitas penyusunan Laporan Keuangan. Implementasi SPI pada Instansi Pemerintah juga terindikasi berkorelasi dengan penyusunan Laporan Keuangan yang berkualitas. Penelitian ini juga bertujuan untuk mengetahui adanya pengaruh antara motivation-hygiene, kompetensi, dan implementasi SPI dalam penyusunan Laporan Keuangan Pemerintah. Penelitian dilakukan dengan pengumpulan dan analisa data dari satuan kerja di Kementerian Kesehatan. Hasil analisa data tersebut selanjutnya digunakan untuk menarik kesimpulan penelitian. Hasil dari penelitian ini menunjukkan bahwa motivation-hygiene, kompetensi, dan implementasi SPI berpengaruh dalam penyusunan Laporan Keuangan Pemerintah.
\end{abstract}

Kata kunci : teori dua faktor, kompetensi, sistem pengendalian intern, motivasi hygiene, laporan keuangan, kualitas laporan keuangan.

\begin{abstract}
Government Institution of Indonesia still experiences many obstacles in providing high-quality Financial Statement. This study aims to identify the factors causing the constraints. Herzberg's Motivation Hygiene Theory and the latest research indicate there's a correlation between Motivation-Hygiene and Financial Statement reporting. Besides Motivation-Hygiene, Human Resources Competency and Effectiveness of Internal Control Implementation possibility correlates with Financial Statement reporting. This research. This study also aims to determine the correlation between Motivation-Hygiene, Human Resources Competency, Effectiveness of Internal Control Implementation, and High-Quality Financial Statement. This Study collects the Ministry of Health data related to this research and analyzes the data to make a brief conclusion. Finally, Motivation-Hygiene, Competence, and Implementation of SPI have a strong correlation both partially and simultaneously with Financial Statements reporting
\end{abstract}

Keywords : herzberg's motivation hygiene theory, internal control, competency, financial statement, financial statement reporting.

\section{PENDAHULUAN}

Transisi menuju akuntansi berbasis akrual pada beberapa Kementerian/Lembaga (K/L) masih mengalami banyak permasalahan penata usahaan dan pencatatan persediaan, aset tetap, dan pengelolaan kas. Masalah tersebut mengakibatkan kesalahan penyajian angka pada Laporan Keuangan. Apabila kesalahan salah saji tersebut tidak bisa dilakukan koreksi dan jumlahnya di atas nilai yang dapat ditoleransi maka hal tersebut dapat mempengaruhi opini atas laporan keuangan.

Ikhtisar Hasil Pemeriksaan Semester (IHPS) I Tahun 2018 yang diterbitkan BPK RI menunjukkan bahwa sebanyak 80 (90,9\%) Laporan Keuangan Kementerian/Lembaga (LKKL) mendapat opini Wajar Tanpa Pengecualian (WTP), 6 LKKL (6,8\%) mendapat opini Wajar dengan Pengecualian (WDP), 
dan 2 LKKL (2,3\%) mendapat opini Tidak Memberikan Pendapat (TMP).

Dari beberapa K/L yang telah memperoleh opini WTP atas Laporan Keuangannya termasuk memiliki tingkat kompleksitas transaksi yang tinggi. Kementerian Kesehatan merupakan salah satu contoh $\mathrm{K} / \mathrm{L}$ dengan kompleksitas tinggi. Laporan Keuangan Kementerian Kesehatan digunakan oleh beberapa stakeholder. Semakin tingginya kompleksitas pada suatu entitas berpotensi menyebabkan terjadinya kesalahan penyajian yang mempengaruhi opini atas Laporan Keuangan. Untuk itu, Kementerian Kesehatan harus terus meningkatkan kualitas penatausahaan keuangannya agar kesalahan penyajian angka pada Laporan Keuangan dapat diminimalisir atau setidaknya dapat ditelusuri.

Laporan Keuangan harus memiliki kualitas antara lain handal, relevan, dapat dibandingkan, dan mudah dipahami. Laporan Keuangan harus bebas dari salah saji sehingga dalam menyusun rencana teknokratik untuk menyusun Renstra didasarkan atas data yang tidak menyesatkan. Laporan Keuangan juga harus menyajikan informasi yang relevan untuk pengambilan keputusan. Laporan Keuangan harus dapat dibandingkan dan mudah dipahami bagi seluruh stakeholder pengguna Laporan Keuangan untuk pengambilan keputusan.

Hasil penelitian menunjukkan bahwa Kualitas Laporan Keuangan berkaitan dengan kompetensi penyusun laporan keuangan di mana kompetensi fungsional dan kognitif memiliki peranan penting meningkatkan kualitas laporan keuangan (Runtuwene, 2017, Wati, et all, 2014, Pradono dan Basukianto, 2015, Nurdianto, 2018). Dengan demikian, kualitas Laporan Keuangan Kementerian Kesehatan bergantung pada PNS yang bertugas menyusun Laporan Keuangan.

Motivasi dan lingkungan kerja sebagaimana dijelaskan dalam teori dua faktor merupakan faktor penting dalam meningkatkan kinerja PNS terutama PNS Kementerian Kesehatan yang bertugas dalam menyusun Laporan Keuangan. Semakin tinggi motivasi PNS artinya PNS puas dalam bekerja sehingga output kinerja (Laporan Keuangan) dapat semakin baik (Dartey, Baah, dan Amoako, 2011). Sedangkan lingkungan kerja yang baik akan memberikan rasa aman dalam bekerja dan pada akhirnya akan meningkatkan output kinerja PNS yang menyusun Laporan Keuangan (Lodhrakentjanal dan Elvira Luthan, 2016, serta Syariendra, Basri, Fahlevi, 2018).

Penatausahaan keuangan juga tidak terlepas dari implementasi Sistem Pengendalian Intern (SPI) organisasi itu sendiri. Penelitian-penelitian terkait SPI menunjukkan bahwa semakin kuat kegiatan pengendalian atas penggunaan sistem informasi akutansi dalam penyusunan atas laporan keuangan semakin baik kualitas laporan keuangan tersebut (Agung dan Gayatri, 2018). Hal tersebut dilakukan dengan meningkatkan implementasi pengendalian umum (Hamdani, 2010) dan Pengendalian Aplikasi meliputi Pengendalian Input, Pengendalian Proses, dan Pengendalian Output (Ariana, 2010).

Berdasarkan fenomena-fenomena tersebut, penulis ingin melakukan pengujian teori-teori yang berlaku sebelumnya berdasarkan analisa dari bukti empiris (Cresswell, 2016:8, dan Silalahi, 2015:7) mengenai "Analisa Faktor-Faktor yang Mempengaruhi Kualitas Laporan Keuangan (Studi pada Kementerian Kesehatan)" dengan pertanyaanpertanyaan penelitian sebagai berikut:

a. Apakah tingkat motivation-hygiene, kompetensi SDM, dan implementasi SPI secara bersamasama (simultan) berpengaruh terhadap kualitas laporan keuangan?

b. Apakah tingkat motivation-hygiene berpengaruh secara parsial terhadap kualitas laporan keuangan?

c. Apakah tingkat kompetensi SDM berpengaruh secara parsial terhadap kualitas laporan keuangan?

d. Apakah besaran implementasi SPI berpengaruh secara parsial terhadap kualitas laporan keuangan?

\section{LANDASAN TEORI}

\section{Kualitas Laporan Keuangan}

Secara teori terdapat dua pandangan tentang akuntansi yaitu pandangan berdasarkan teori akuntansi normatif dan teori akuntansi positif. Teori akuntansi normatif lebih berpandangan bahwa akuntansi dikembangkan berdasarkan value judgement atau apa yang seharusnya dilakukan oleh entitas dalam akuntansi (Ghozali dan Chairi:35, 2013). Hasil akhir dari teori akuntansi normatif adalah suatu pernyataan atau proposisi yang mengharuskan atau mewajibkan dalam praktik akuntansi (Salampessy, 2012). Dengan demikian kualitas laporan keuangan dinilai dari bagamana praktik akuntansi yang digunakan untuk menyusun laporan keuangan telah benar-benar mencatat berdasarkan data dan informasi historis.

Pada perkembangannya Watt dan Zimmerman (2006:2) berpandangan bahwa teori normatif terlalu sederhana dan tidak memberikan dasar pemikiran yang kuat. Pada kenyataannya, pendekatan normatif tidak siap dipakai dalam praktik (Setijaningsih, 2012) dan bersifat parsial sehingga perlu pemahaman deskriptif berfungsinya sistem akuntansi akuntansi dalam praktik yang nyata 
(Salampessy, 2012). Hal tersebut memunculkan teori akuntansi positif yang lebih mengedepankan penjelasan dan prediksi praktik akuntansi (Scott, 2009:284-294). Baik teori normatif dan positif telah mendasari lahirnya kerangka dasar konseptual (Nahar, 2004) yang menjadi dasar Prinsip akuntansi, Standar Akuntansi Pemerintah (SAP) dan kebijakan-kebijakan akuntansi yang berlaku di entitas.

Hubungan antara teori akuntansi berlanjut sampai dengan tujuan pelaporan keuangan. Adapun tujuan dari laporan keuangan adalah memberikan informasi yang relevan, mudah dipahami, mudah dipahami, dapat dibandingkan, dan terverifikasi (Latjandu, et all, 2014). Hal tersebut menjadi karakteristik kualitatif dan kuantitatif laporan keuangan. Standar Akuntansi Pemerintahan menjadi acuan bagi penyusunan laporan keuangan agar laporan keuangan memenuhi karakteristik kualitatif dan kuantitatif laporan keuangan (Setyowati, et all, 2016). Karakteristik Kualitatif Laporan Keuangan terdiri dari tingkat kehandalan, kemudahan dipahami, relevansi, dan dapat dibandingkan (Apriliani, et all, 2015). Kehandalan bebas dari kesalahan yang menyesatkan (Siswanti dan Rizani, 2017). Sedangkan tingkat relevansi adalah laporan keuangan relevan digunakan untuk pengambilan keputusan (Apriliani, et al, 2015).

\section{Teori Dua Faktor Motivation-Hygiene}

Salah satu teori yang mempengaruhi motivasi SDM untuk menyusun laporan keuangan adalah Teori Dua Faktor Motivation-Hygiene. Teori tersebut memandang bahwa motivasi bekerja dipengaruhi oleh dua hal yaitu faktor lingkungan dan faktor kepuasan dalam bekerja (Dartey, Baah, dan Amoako, 2011). Teori tersebut menjelaskan mekanisme motivasi pegawai di mana faktor hygiene merupakan kondisi tempat kerja secara keseluruhan sedangkan faktor motivation merupakan kondisi tempat kerja yang berpengaruh langsung pada individu pegawai (Bockman, V.M, 1971 : 155-199, Evans, M. G., 1970:32-35).

Semakin baik faktor Motivation-Hygiene di tempat kerja SDM yang membuat laporan keuangan maka dapat meningkatkan kualitas atas laporan keuangan (Lodhrakentjanal dan Elvira Luthan, 2016, serta Syariendra, Basri, Fahlevi, 2018).

Penelitian Ibrahim, et all (2016) menujukkan bahwa faktor Motivation-Hygiene berpengaruh terhadap potensi akuntan yang menyusun laporan keuangan. Motivasi SDM juga telah dibuktikan berpengaruh positif terhadap kualitas laporan keuangan (Runtuwene, 2017). Penelitian lain juga mengungkapkan bahwa motivasi memberikan pengaruh positif bagi penyusunan laporan keuangan (Sutawan, 2015). Selain itu, penelitian yang menjadikan motivasi sebagai variabel komitmen organisasi juga menunjukkan pengaruh positif terhadap kualitas laporan keuangan (Agung, 2018).

Penelitian yang dilakukan oleh Kang dan Lin (2011) menunjukkan bahwa motivasi dapat meningkatkan konsistensi pencatatan akuntansi. Namun, penelitian yang dilakukan Staden (2006) menunjukkan bahwa motivasi tidak mempengaruhi voluntary disclosoure karena pengaruh hipotesa dari political cost theory. Sedangkan menurut Gajic dan Medved (2010) motivasi berpengaruh pada kinerja karyawan yang melaksanakan fungsi akuntansi.

Penelitian-penelitian sebelumnya menggunakan indikator reward and punishment dan job promotion sebagai dasar memperoleh nilai variabel motivasi karyawan (Sutawan, 2015 dan Agung, 2018) yang selanjutnya dihubungkan langsung dengan kualitas laporan keuangan. Penelitian yang lebih rinci atas indikator teori dua faktor hanya menghubungkan dengan output kerja karyawan Faktor MotivationHygiene yang baik dapat meningkatkan motivasi kerja SDM (Lodhrakentjanal dan Elvira Luthan, 2016, serta Syariendra, Basri, Fahlevi, 2014). Oleh karena itu penelitian ini mencoba menggunakan seluruh indikator teori dua faktor terhadap kualitas laporan keuangan.

\section{Kompetensi SDM}

Kondisi tempat kerja yang baik dapat meningkatkan motivasi SDM yang bertugas namun tanpa didukung kompetensi SDM yang baik berpotensi terjadi kesalahan dalam penyusunan laporan keuangan (Satrio, Yuhertiana, dan Hamzah, 2016). Kompetensi adalah ciri seseorang yang dapat dilihat dari keterampilan, pengetahuan, dan kemampuan yang dimilikinya dalam hal menyelesaikan tugas tugas yang dibebankan kepadanya (Wati, Herawati, dan Sinarwati, 2014). Kompetensi juga didefinisikan sebagai keterampilan yang harus dimiliki untuk menghadapi tantangan pekerjaan (Bradley dan Keating, 2017). Dengan demikian, SDM yang kompeten diperlukan untuk tugas dan tantangan dalam menyusun laporan keuangan.

Kompetensi sendiri bergantung pada tingkat pendidikan, pengalaman, dan pelatihan (Satrio, Yuhertiana, dan Hamzah, 2016). Pandangan lain yang lebih lengkap dari penelitian tersebut mengungkapkan bahwa kompetensi sendiri terdiri dari Komptensi Kognitif, Kompetensi Fungsional, Kompetensi Personal, dan Kompetensi Etika (Makulova, et all, 2015 dan Fukuda 2018). Penelitian lain menjelaskan tentang komponen 
kompetensi yang dikembangkan dari Learning Theory menunjukkan bahwa kompetensi merupakan perpaduan antara keterampilan dan perilaku (Lavioe, 2018). Dalam hal ini penulis lebih setuju pandangan Makulova dan Fukuda terkait dengan komponen kompetensi.

Kompetensi Kognitif adalah kompetensi teoritis berupa pengetahuan dan kemampuan membuat analisa atau menyusun hubungan sebab dan akibat dari suatu masalah. Kompetensi Kognitif diperoleh dari pendidikan formal oleh karena itu tingkat pendidikan SDM menggambarkan Kompetensi Kognitif dari SDM (Nuria, 2018). Prestasi atau predikat nilai pada setiap jenjang pendidikan juga menggambarkan Kompetensi Kognitif dari SDM (Makulova, et all, 2015).

Kompetensi Fungsional adalah kompetensi keterampilan untuk menyelesaikan tugas spesifik dari suatu pekerjaan. Kompetensi keterampilan lebih mengarah pada pengalaman dan pelatihan teknis SDM dalam pekerjaannya (Nuria, 2018).

Kompetensi personal merupakan kompetensi pribadi SDM tersebut yang mendukung keefektifan dalam bekerja. Kompetensi personal lebih mengarah pada tingkat kestabilan emosional dalam melaksanakan tugasnya. Kompetensi personal dapat diukur dari kemampuan SDM bekerja di bawah tekanan seperti tekanan waktu (Wardhian, 2016) dan tekanan beban kerja/workload (Tahir, 2018), Sedangkan kompetensi etika lebih mengarah pada kemampuan SDM untuk menjaga etika dalam bekerja. Kompetensi etika dinilai dari kemampuan SDM menyelesaikan masalah pekerjaan dengan memperhatikan norma dan peraturan yang berlaku (Menzel, 2016).

Penelitian-penelitian sebelumnya rata-rata menggunakan indikator kompetensi kognitif dan profesional untuk mengukur variabel kompetensi. Pada penelitian ini penulis ingin meneliti bagaimana indikator Komptensi Kognitif, Kompetensi Fungsional, Kompetensi Personal, dan Kompetensi Etika (Makulova, et all, 2015 dan Fukuda 2018) dapat mempengaruhi kualitas laporan keuangan.

\section{Implementasi Sistem Pengendalian Intern}

Sistem Pengendalian Intern (SPI) merupakan proses/prosedur untuk melindung aset perusahaan, pengelola informasi yang akurat, dan memastikan peraturan hukum yang berlaku (Rokhlinasari dan Hidayat, 2016). Pendapat lain mengenai SPI adalah suatu rangkaian proses yang didesain untuk meningkatkan implementasi dan efisiensi dari kegiatan finansial dan tujuan organisasi (Aramide dan Bashir, 2015). SPI merupakan bagian penting dari perkembangan manajemen sumber daya ekonomi modern (Chen dan Shi, 2012). SPI juga didefinisikan oleh Committee of Sponsoring Organizations of the Treadway Commission (COSO) sebagai serangkaian proses yang didesain oleh dewan direksi, manajemen, atau personel lain dengan tujuan untuk memberikan reasonable assurance untuk pencapaian tujuan secara efektif dan efisien.

Pemerintah telah menerbitkan Peraturan Pemerintah Nomor 60 Tahun 2008 tentang Sistem Pengendalian Intern Pemerintah yang mewajibkan penyelenggaraan unsur pengenalian internal di seluruh instansi pemerintah. Oleh karena itu, seluruh instansi menyelenggarakan SPI terutama dalam kegiatan akuntansinya. Kelemahan SPI sendiri didefinisikan dengan ketidakefektifan penyelenggaraan SPI (Cheng dan Shi, 2012, Aramide dan Bashir, 2015, serta Rokhlinasari dan Hidayat, 2016).

Pengukuran variabel Implementasi SPI lebih difokuskan pada kegiatan pengendalian umum dalam penyusunan atas laporan keuangan (Agung dan Gayatri, 2018). Sehingga indikator dari implementasi SPI menggunakan implementasi pengendalian umum (Hamdani, 2010) meliputi Lingkungan Pengendalian, Penilaian Risiko, Kegiatan Pengendalian, Informasi dan Komunikasi serta Aktifitas Monitoring.

\begin{tabular}{|c|c|c|}
\hline Variabel & Dimensi & Penjelasan Dimensi \\
\hline \multirow{5}{*}{$\begin{array}{l}\text { Kualitas } \\
\text { Laporan } \\
\text { Keuangan } \\
\text { (Y) }\end{array}$} & Y1 & Jurnal Koreksi \\
\hline & Y2 & Latent - Relevan \\
\hline & Y3 & Latent - Handal \\
\hline & Y4 & Latent - Dapat Dibandingkan \\
\hline & Y5 & Latent - Mudah Dipahami \\
\hline \multirow{2}{*}{$\begin{array}{l}\text { Motivation } \\
\text { Hyigiene (X1) }\end{array}$} & $\mathrm{M}$ & Latent - Motivation \\
\hline & $\mathrm{H}$ & Latent - Hygiene \\
\hline \multirow{4}{*}{$\begin{array}{l}\text { Kompetensi } \\
(X 2)\end{array}$} & $\mathrm{K}$ & Latent-Kognitif \\
\hline & $\mathrm{F}$ & Latent - Fungsional \\
\hline & $P$ & Latent - Personal \\
\hline & $E$ & Latent - Etika \\
\hline \multirow{5}{*}{$\begin{array}{l}\text { Implementasi } \\
\text { SPI } \\
\text { (X3) }\end{array}$} & LP & Latent - Lingkungan Pengendalian \\
\hline & RA & Latent - Risk Assesment \\
\hline & $\mathrm{KP}$ & Latent - Kegiatan Pengendalian \\
\hline & $\mathrm{KI}$ & Latent - Komunikasi dan Informas \\
\hline & $\mathrm{ME}$ & Latent - Monitoring dan Evaluasi \\
\hline
\end{tabular}

Penelitian sebelumnya rata-rata menggunakan indikator COSO untuk mengukur implementasi SPI (Sutawan, Darmawan, Tuniarta, 2015 serta Agung dan Gayatri, 2018) serta indikator ada tidaknya Sistem Informasi (Pradono, 2015, Setyowati, Isthika, Pratiwi, 2016, Juwita, 2013, Runtuwene, 2017, Agung dan Gayatri, 2018. Pada penelitian ini juga menggunakan indikator COSO untuk mengukur variable implementasi SPI yaitu diukur dari kegiatan pengendalian umum meliputi Lingkungan Pengendalian, Penilaian Risiko, 
Kegiatan Pengendalian, Informasi dan Komunikasi serta Aktifitas Monitoring (Hamdani, 2010). Ringkasan Operasionalisasi Variabel seperti pada Tabel 1 yang di susun berdasrkan landasan teori.

\section{METODE PENELITIAN}

Penelitian ini menggunakan desain kausalitas dengan menggunakan data primer dan sekunder. Penelitian ini merupakan penelitian lapangan dengan unit analisis Satuan Kerja pada Kementerian Kesehatan. Penelitian ini menghitung kecukupan sampel sebesar 69 sampel dari 217 populasi Satuan Kerja pada Kementerian Kesehatan dengan Slovin Formula yaitu

$$
n=\frac{217}{1+217(0,10)^{2}}=68,45
$$

Peneliti menentukan tingkat kesalahan yang dapat ditoleransi sebesar $10 \%$.

Selanjutnya analisa dilakukan dengan Analisa Statistik Deskriptif dan Inferensial. Analisa Deskriptif berupa penyajian data, ukuran pemusatan data, ukuran letak, dan keragaman data. Analisa Inferensial pada penelitian ini adalah Partial Least Square (PLS). Adapun peneliti menggunakan aplikasi bantu SmartPLS. Pengujian meliputi evaluasi model pengukuran (outer model) dan dan model struktural (inner model) untuk menjawab hipotesa berikut.

a. Motivation-Hygiene, Kompetensi SDM, dan Implementasi SPI berpengaruh secara simultan terhadap Kualitas Laporan Keuangan dengan

b. Motivation-Hygiene berpengaruh secara parsial terhadap Kualitas Laporan Keuangan.

c. Komptensi SDM berpengaruh secara parsial terhadap Kualitas Laporan Keuangan.

d. Implementasi SPI berpengaruh secara parsial terhadap Kualitas Laporan Keuangan.

\section{HASIL DAN PEMBAHASAN}

\section{Analisa Deskriptif}

Data dalam penelitian ini meliputi adalah data dari 69 satuan kerja dengan rincian sebagai berikut.

\begin{tabular}{|l|c|r|}
\hline Jumlah & $\mathbf{6 9}$ & $\mathbf{1 0 0} \%$ \\
\hline \multicolumn{2}{|c|}{ Responden Pengguna } \\
\hline KPA Satker & 67 & $97,10 \%$ \\
\hline Biro Perencanaan & 1 & $1,45 \%$ \\
\hline Biro Hukum & 1 & $1,45 \%$ \\
\hline Jumlah & $\mathbf{6 9}$ & $\mathbf{1 0 0} \%$ \\
\hline
\end{tabular}

Selanjutnya pemusatan data, ukuran letak, dan keragaman data disajikan dalam tabel di bawah ini.

Tabel 3 Pemusatan, Ukuran, Keragaman Data

\begin{tabular}{|l|l|r|r|r|r|}
\hline Variabel & Ind & Mean & Med & S.Dev & \multicolumn{1}{c|}{ Kurtosis } \\
\hline \multirow{3}{*}{$\begin{array}{l}\text { Kualitas } \\
\text { Laporan }\end{array}$} & $\mathrm{Y} 1$ & 4,667 & 5 & 0,927 & 6,198 \\
\cline { 2 - 6 } $\begin{array}{l}\text { Keuangan } \\
\text { (Y) }\end{array}$ & $\mathrm{Y} 2$ & 6,783 & 7 & 2,371 & $-1,121$ \\
\cline { 2 - 6 } & $\mathrm{Y} 3$ & 6,754 & 7 & 1,929 & $-0,5$ \\
\cline { 2 - 6 } & $\mathrm{Y} 4$ & 6,217 & 6 & 1,856 & $-0,06$ \\
\cline { 2 - 6 } & $\mathrm{Y} 5$ & 6,725 & 7 & 1,963 & $-0,296$ \\
\hline $\begin{array}{l}\text { Motivation } \\
\text { Hyigiene (X1) }\end{array}$ & $\mathrm{M}$ & 34,101 & 37 & 7,267 & $-0,183$ \\
\cline { 2 - 6 } $\begin{array}{l}\text { Kompetensi } \\
\text { (X2) }\end{array}$ & $\mathrm{H}$ & 37,652 & 40 & 7,927 & $-0,132$ \\
\cline { 2 - 6 } & $\mathrm{F}$ & 11,435 & 12 & 2,694 & $-0,119$ \\
\cline { 2 - 6 } & $\mathrm{P}$ & 7,449 & 8 & 1,806 & 0,272 \\
\cline { 2 - 6 } & $\mathrm{E}$ & 7,638 & 8 & 1,963 & 0,188 \\
\hline \multirow{3}{*}{$\begin{array}{l}\text { Implementasi } \\
\text { SPI } \\
\text { (X3) }\end{array}$} & $\mathrm{LP}$ & 7,464 & 8 & 1,953 & $-0,141$ \\
\cline { 2 - 6 } & $\mathrm{RA}$ & 7,783 & 8 & 1,768 & $-0,392$ \\
\cline { 2 - 6 } & $\mathrm{KP}$ & 7,522 & 8 & 1,854 & $-0,219$ \\
\cline { 2 - 6 } & $\mathrm{KI}$ & 7,609 & 8 & 1,835 & 0,894 \\
\cline { 2 - 6 } & $\mathrm{ME}$ & 7,549 & 8 & 1,906 & 0,223 \\
\hline
\end{tabular}

Secara umum pemusatan dan letak data terpusat dapat dilihat dari nilai kurtosis tidak lebih dari 1,96 maupun tidak kurang dari -1,96. Rata-rata data tersebut terdistribusi normal untuk seluruh indikator kecuali indikator kualitas LK dari perspektif jurnal korekasi (Y1) dan Relevansi (Y2). Namun demikian, untuk memastikan indikator tersebut tepat digunakan dalam pengukuran dalam suatu variabel maka model tersebut akan diuji lebih lanjut dalam model pengukuran (Outer Model).

\section{Analisa Inferensia}

Analisa Inferensia dengan PLS dilakukan secara berurutan dari pengujian model pengukuran (outer model) baru dilanjutkan dengan pengujian model struktural (inner model). Adapun rinciannya adalah sebagai berikut.

\section{a. Model Pengukuran (Outer Model)}

Tabel 2 Profil Responden

\begin{tabular}{|c|c|c|}
\hline Jenis Satker & Frekuensi & $\%$ \\
\hline \multicolumn{3}{|c|}{ Responden Pelaksana } \\
\hline Rumah Sakit & 30 & $43,48 \%$ \\
\hline Politeknik Kesehatan & 28 & $40,58 \%$ \\
\hline KKP dan BTKLPP & 8 & $11,59 \%$ \\
\hline Balai dan Biro & 3 & $4,35 \%$ \\
\hline Jumlah & 69 & $100 \%$ \\
\hline \multicolumn{3}{|c|}{ Responden Pemeriksa } \\
\hline Auditor BPK & 45 & $65,22 \%$ \\
\hline Auditor Inspektorat & 24 & $34,78 \%$ \\
\hline
\end{tabular}




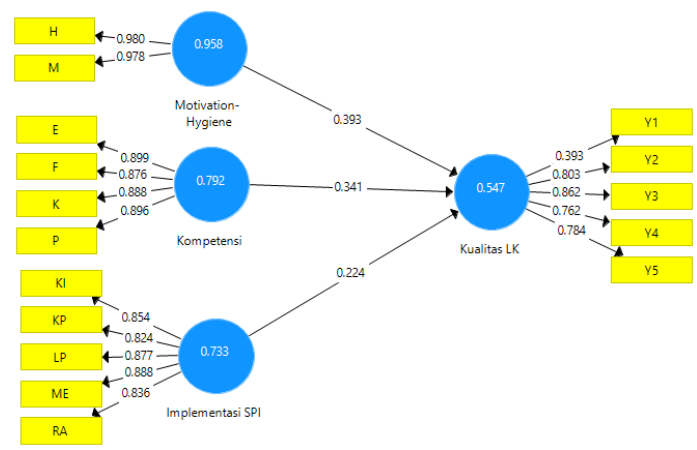

Gambar 1. Model Pengukuran

Pengujian model pengukuran meliputi pengujian validitas dan reliabilitas. Pada gambar tersebut tergambarkan bahwa data tersebut dinyatakan valid karena memenuhi syarat pengujian Convergent Validity dan Descriminant Validity. Convergent Validity diuji dengan memperhatikan nilai Average Variance Extracted (AVE) harus di atas 0,5 maupun 0,7. Dari gambar 1 menunjukkan bahwa nilai AVE diatas 0,5. Sedangkan pengujian Descriminant Validity nilai cross loading yang lemah yaitu perspektif Jurnal Koreksi (Y1). Setelah pengujian validitas pengujian dilakukan dengan pengujian reliabilitas yaitu Composite Reliabilty dan Alpha Cronbach. Adapun hasil pengujian reliabilitas adalah menunjukkan bahwa data tersebut reliabel karena memiliki angka Composite Reliability diatas 0,7 dan Alpha Cronbach di atas 0,6 dengan dincian sebagai berikut.

Tabel 4 Pengujian Reliabilitas

\begin{tabular}{|l|c|c|}
\hline \multicolumn{1}{|c|}{ Variabel } & $\begin{array}{c}\text { Composite } \\
\text { Reliability }\end{array}$ & $\begin{array}{c}\text { Alpha } \\
\text { Cronbach }\end{array}$ \\
\hline Kualitas Laporan Keuangan (Y) & 0,909 & 0,909 \\
\hline Motivation Hyigiene (X1) & 0,912 & 0,912 \\
\hline Kompetensi (X2) & 0,794 & 0,774 \\
\hline Implementasi (X3) & 0,957 & 0,956 \\
\hline
\end{tabular}

\section{b. Model Struktural (Inner Model)}

Pengujian model struktural dilakukan untuk menjawab hipotesa penelitian. Pengujian model struktural dilakukan dengan bootstraping untuk mengetahui nilai $R$-Square, nilai koefisien jalur, dan tingkat signifikansi. Adapun hasil pengujian model struktural secara keseluruhan digambarkan pada Gambar 2. Gambar 2 menunjukkan bahwa secara keseluruhan variabel memiliki kekuatan jalur yang signifikan karena memiliki t-statistics di atas 1.29492 (Angka Presentase Distribusi pada Tingkat Tolerasi 10\% dan Jumlah Sampel 69). Sedangkan kekuatan jalurnya adalah sebesar 0,393, 0,341, dan 0,224. Hasil Bootstraping juga menunjukkan nilai
Rsquare sebesar 1,109 dan Adjusted Rsquare sebesar 1,114 atau lebih besar dari 0,7.

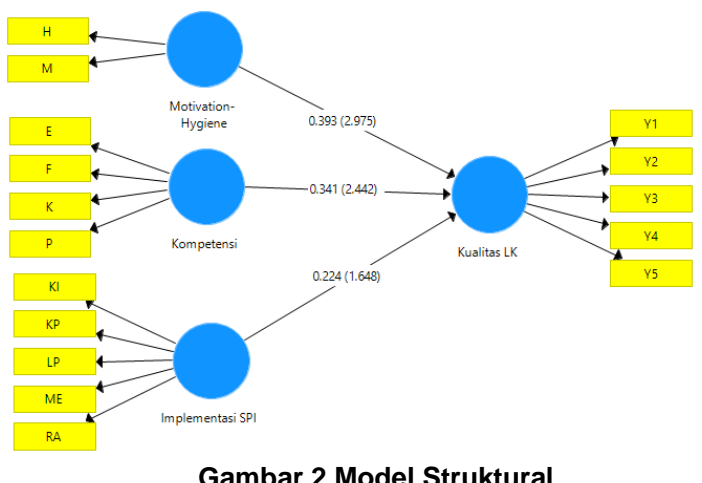

Pengujian model struktural menjawab hipotesa penelitian dengan rincian sebagai berikut.

a. Motivation-Hygiene, Kompetensi SDM, dan Implementasi SPI berpengaruh secara simultan terhadap Kualitas Laporan Keuangan. Hal ini ditunjukkan nilai Rsquare di atas 0,7 ;

b. Motivation-Hygiene berpengaruh secara parsial terhadap Kualitas Laporan Keuangan. Hal ini ditunjukkan nilai t-statistic adalah sebesar 2,975 atau melebihi 1,29492. Adapun dengan koefisien jalur yang dibentuk adalah sebesar 0,393;

c. Komptensi SDM berpengaruh secara parsial terhadap Kualitas Laporan Keuangan. Hal ini ditunjukkan nilai $t$-statistic adalah sebesar 2,2442 atau melebihi 1,29492. Adapun dengan koefisien jalur yang dibentuk adalah sebesar 0,341 ;

d. Implementasi SPI berpengaruh secara parsial terhadap Kualitas Laporan Keuangan. Hal ini ditunjukkan nilai $t$-statistic adalah sebesar 1,648 atau melebihi 1,29492. Adapun dengan koefisien jalur yang dibentuk adalah sebesar 0,224.

Secara matematis pengujian kekuatan antar jalur tersebut adalah sebagai berikut.

$$
Y=0,393 \times 1+0,341 \times 2+0,224 x 3
$$

\section{KESIMPULAN DAN SARAN}

Hasil penelitian ini menunjukkan bahwa Herzberg's Theory of Motivation and Hygiene berlaku dalam proses penyusunan Laporan Keuangan. Untuk itu Kementerian Kesehatan harus terus menerus memotivasi pegawainya dan menciptakan lingkungan kerja yang baik agar kualitas Laporan Keuangan semakin meningkat. Selain itu, Kompetensi dan Implementasi SPI juga 
ikut mempengaruhi proses penyusunan Laporan Keuangan. Dengan demikian Kementerian Kesehatan juga harus terus meningkatkan kompetensi pegawainya dan mengimplementasikan SPI secara efektif.

\section{DAFTAR PUSTAKA}

Agung. Tut Madiguna dan Gayatri, (2018), Analisis Faktor-Faktor yang Mempengaruhi Kualitas Laporan Keuangan Pemerintah Daerah Kabupaten Karangasem, Jurnal UNUD

Apriliani., Ni Kadek Alit , Dr. Edy Sujana,SE,Msi,AK ., Gede Adi Yuniarta, (2015), Pengaruh Penyajian Laporan Keuangan, Karakteristik Kualitatif, Dan Aksesibilitas Terhadap Transparansi Laporan Keuangan Pemerintah Daerah (Studi Empiris Pada Satuan Kerja Perangkat Daerah Kabupaten Klungkung), Jurnal Undhiksa

Aramide, Sanusi Fasilat,. Bashir, Mustapha Muhammed,(2015), the Effectiveness Of Internal Control System And Financial Accountability At Local Government Level In Nigeria, International Journal of Research in Business Management

Ariana, I Made. (2010). Pengendalian Aplikasi Sistem Informasi Akuntansi Berbasis Komputer. Jurnal Valid. 7. 22-32.

Baah, Kwasi Dartey, Amoako George Kofi (2011), Application of Frederick Herzberg's TwoFactor theory in assessing and understanding employee motivation at work: a Ghanaian Perspective, European Journal Business and Management

Bockman, V. M.: The Herzberg Controversy. Personnel Psychology, Summer 1971, Hal $155-189$

Cheng, Hongmin, Yanan Shi (2012), Empirical Study on the Correlation between the Internal Control and Enterprise Value Based on the Information System, Jurnal Of Computer

Cooper, Terry \& C. Menzel, Donald \& , eds. (2013). Achieving Ethical Competence for Public Service Leadership. M.E. Sharpe, 2013.

Creswell, John W. 2016. "Research Design", Pustaka Pelajar, 2016. Jakarta

Evans, M. G.: Herzberg's Two-Factor Theory of Motivation: Some Problems and a Suggested Test. PJ, January 1970, Hal. $32-35$

Fukuda, Yasue \& Fukuda, Koji. (2018). Parents' attitudes towards and perceptions of involving minors in medical research from the Japanese perspective. BMC Medical Ethics. 19. 10.1186/s12910-018-0330-1.

Gajic, Ljubica,. Medved, Ivana, (2010), Financial Segment Reporting in The Function of Building Motivation and Rewarding System, Business and Economiv Horizon Journal

Ghozali, I. dan Chariri, A. 2007. Teori Akuntansi. Badan Penerbit Universitas Diponegoro, Semarang

Hamdani, Romadhon (2010), penerapan sistem pengendalian intern berbasis komputer, berbasis sistem informasi akuntansi pada cv. Syahid husada surabaya, UPN

Ibrahim, S.N.S., Pauzi N.F.M, Shamsudin Andriana, Karim M.S., Ahmad Khairah (2016), Motivating Factors for Sustainable Accountant Potential in Malaysia, ICGA, DOI: 10.1051.shsconf/20173600035, 2016

Jaradat, Raed \& Keating, Charles \& Bradley, Joseph. (2017). Individual Capacity and Organizational Competency for Systems Thinking. IEEE Systems Journal. PP. 1-8. 10.1109/JSYST.2017.2652218.

Kang, Gerui, Lin, Jerry W. (2011) Effect of the Type Accounting Standard and Motivation on Financial Reporting Decision, S.I. Vol 18. ISSN 2622-2167

Latjandu Imelda, (2014) Faktor-Faktor Yang Mempengaruhi Kualitaslaporan Keuangan Pemerintah Daerah Di Kabupatenkepulauan Talaud, Ejournal Unsrat

Lavioe, (2018), Learning theories and tools for the assessment of core nursing competencies in simulation: A theoretical review, NCBI

Lodhrakentjana Baja, Elvira, Luthan (2014), Motivasi, Kepuasan Kerja, Komitmen Pegawai Akuntansi dan Kualitas Laporan Keuangan Pemerintah Daerah pada Pemerintah Kota Depok, JURNAL RISET AKUNTANSI \& PERPAJAKAN, ISSN 23391545 Jakarta

Nahar, Aida (2009), Pengaruh Penyajian Laporan Keuangan Daerah dan Aksesibilitas Laporan Keuangan Daerah Terhadap Transparansi Dan Akuntabilitas Pengelolaan Keuangan Daerah Kabupaten Jepara, Jurnal Undip

Nurdiano (2018), Analisis Hasil Audit Laporan Keuangan Pemerintah Daerah Seluruh Indonesia, UGM

Nuria, Estetika (2018), Pengaruh Gaya Kepemimpinan, Dan Komitmen Organisasi Terhadap Kinerja Pegawai (Studi Pada Pegawai Badan Pemeriksa Keuangan Republik Indonesia), Repository Universitas Padjadjaran 
Rokhlinasari, Sri,. Hidayat, Adi (2016), Pengaruh Sistem Pengendalian Internal Terhadap Kualitas Laporan Keuangan Pada Bank BJB Syariah Cirebon, Jurnal Am-Amwal

Salampessy, Zulkarim (2012), Kritik Terhadap Teori Akuntansi Positif, El Muhasaba: Jurnal Akuntansi

Satrio, M. Dimas, Yuhertiana, Indrawati Yuhertiana, Hamzah, Ardi Hamzah (2016), Implementasi Standar Akuntansi Pemerintah Berbasis Akrual di Kabupaten Jombang, Jurnal Akuntansi dan Keuangan, Vol. 18, No. 1, Mei 2016, 59-70

Scott, William R, 2009. Financial Accounting Theory. Fifth Edition. Canada Prentice Hall

Setijaningsih. 2012. Teori Akuntansi Positif dan Konsekuensi Ekonomi. Jurnal Akuntansi Volume XVI, No. 03 September 2012. Universitas Tarumanegara Jakarta

Setyowati, Lilis, Isthika, Wikan, dan Pratiwi, Ririh Dian (2016), Faktor-Faktor Yang Mempengaruhi Kualitas Laporan Keuangan Pemerintah Daerah Kota Semarang, Kinerja Journal of Business

Silalahi, Ulber. 2015. "Metode Penelitian Sosial Kuantitatif", PT Refika Aditama, 2015. Jakarta

Sutawan, I Made Edy (2015), Pengaruh Stres Kerja, Motivasi, dan Sistem Pengendalian Intern Terhadap Kualitas Laporan Keuangan Koperasi, E-Jurnal UPG

Tahir, Nurbiah, (2018), Identifikasi Model Kompetensi Sumber Daya Aparatur di Sekretariat Pemerintah Kota Makassar, Administrare Journal, Vol 3.

Tulegenovna Makulova, Aimzhan \& Mukhtashevna Alimzhanova, Gaukhar \& Mustafaevna Bekturganova, Zhanar \& Asetovna Umirzakova, Zaure \& Tulegenovna Makulova, Laura \& Meirambaevna Karymbayeva, Kulzinat. (2015). Theory and Practice of Competency-Based Approach in Education. International Education Studies. 8. 10.5539/ies.v8n8p183.

Villiers, Charl de,. Staden, Chris J. Van,. Accounting, Organizations and Society, 2006, vol. 31, issue 8, 763-781

Wardhian, Gama (2016), Efektivitas Penggunaan Modul Pembelajaran Kimia, Jurnal FKIP, UNS

Watts R. and J.L. Zimmerman. 1986. Positive Accounting Theory. New York: Prentice-Hall. 